\title{
TRABALHO ESCRAVO E A INSANIDADE DESUMANA EXPRESSADA NO OESTE DA BAHIA
}

\author{
Tássio Barreto Cunha ${ }^{1}$
}

Resumo: A escravidão enquanto uma prática degradante do trabalho persistiu no Oeste da Bahia nas últimas décadas enquanto um dos elementos que representa a continuidade de mecanismos da acumulação primitiva, exercida principalmente por grandes grupos empresariais detentores e/ou vinculados a modernas empresas agrícolas. Este foco ocorreu essencialmente na busca do aumento da taxa de lucro, em que a intensificação da mais-valia, da renda e dos juros, alicerçados também por essa prática, fizeram muitos empresários atuantes no setor agropecuário no Oeste da Bahia "lucrarem como capitalistas e pagarem como detentores de escravos". Em uma condição que a produção capitalista de relações não capitalistas se expressa além de formas da reprodução ampliada do capital, mas também a reprodução ampliada das contradições do capitalismo. Um movimento contraditório não só de subordinação das relações pré-capitalistas, mas também de criações antagônicas e subordinadas não capitalistas.

Palavras-chave: Trabalho Escravo; Acumulação Primitiva; Oeste da Bahia.

\section{SLAVERY AND UNDERGROUND INSANITY EXPRESSED IN OESTE DA BAHIA}

\begin{abstract}
Slavery as a degrading practice of labor persisted in the Oeste da Bahia in the last decades while one of the elements that represents the continuity of primitive accumulation mechanisms, mainly carried out by large business groups linked to modern agricultural enterprises. This focus was mainly on the search for an increase in the rate of profit, in which the intensification of added value, income, and interest, also underpinned by this practice, made many entrepreneurs active in the agricultural sector in Western Bahia "to profit as capitalists and to pay as slaveholders." In a condition which capitalist production of non-capitalist relations expresses itself in addition to forms of the expanded reproduction of capital, but also the amplified reproduction of the contradictions of capitalism. A contradictory movement not only of subordination of pre-capitalist relations, but also of non-capitalist antagonistic and subordinate creations.
\end{abstract}

Keywords: Slavery; Primitive Accumulation; Oeste da Bahia.

\footnotetext{
${ }^{1}$ Docente do Instituto Federal de Brasília. tassiocunha@gmail.com.

Estudos Geográficos, Rio Claro, 17: 176-192, jan./jun. 2019 (ISSN 1678-698X) http://www.periodicos.rc.biblioteca.unesp.br/index.php/estgeo
} 
Trabalho escravo e a insanidade desumana...

\section{PASSOS INICIAIS}

"A escravização do ser humano não possui fronteiras, mas tem destino".

(Tássio Barreto Cunha)

É necessária a convicção que a barbárie instalada no Oeste da Bahia não se introduziu ontem e tão pouco se restringe apenas a esse território. Essa é uma prática milenar, que possui a busca do controle da terra, da água e do trabalho antes mesmo da emergência do modo capitalista de produção. Em que sempre esteve associada às formas mais extremas de exploração e privação dos direitos humanos, como é observado no Oeste da Bahia. Onde a condição da destruição ambiental, do trabalho forçado, das prisões, as extirpações das populações tradicionais etc., sempre estiveram ligadas as práticas da escravidão ${ }^{2}$, enquanto tirania reconfigurada de "tempos em tempos". Exercida recentemente nessa região da Bahia, sobretudo a partir da abertura da fronteira agrícola e intensificada ao passo que maiores injeções de capitais foram introduzidos na cadeia produtiva.

Porém, é preciso ter em mente que as forças e as relações de produção não se desenvolvem a partir do nada e não nascem de uma única ideia que se põe. Pelo contrário, se formam no interior paradoxal do desenvolvimento da produção existente e nas relações de propriedade herdadas, seja do trabalho e/ou da natureza (MARX, 2013 apud MÉSZÁROS, 2007). Um sentido da própria compreensão dialética da história da vida social, que é a "multiplicidade dos possíveis e a singularidade das circunstâncias". Que deve servir como base para a compreensão do trabalho escravo no Oeste da Bahia, principalmente a partir da concepção que "o próprio capital engendra e reproduz relações não capitalistas de produção, numa coexistência de tempos sociais de datas entre si diversas" (MARTINS, 2015).

A escravidão enquanto uma prática degradante do trabalho persistiu no Oeste da Bahia nas últimas décadas enquanto um dos elementos que representa a continuidade de mecanismos da acumulação primitiva, exercida principalmente por grandes grupos empresariais detentores e/ou vinculados a modernas empresas agrícolas (Tabela 01) ${ }^{3}$. Com foco essencialmente no aumento da taxa de lucro, em que a intensificação da mais-valia, da renda e dos juros, alicerçados também por essa prática fizeram muitos empresários atuantes no setor agropecuário no Oeste da Bahia, "lucrarem como capitalistas e pagarem como detentores de escravos". Em uma condição que a produção capitalista de relações não capitalistas se expressa além de formas de reprodução ampliada do capital, mas também a reprodução ampliada das contradições do capitalismo. Um movimento contraditório não só de subordinação das relações pré-capitalistas, mas também de criações antagônicas e subordinadas não capitalistas (MARTINS, 2015).

\footnotetext{
2 Nesse trabalho não iremos debater o conceito de escravidão. Logo, escravidão, escravidão moderna, escravidão contemporânea e trabalho análogo ao escravo, serão entendidos aqui enquanto sinônimos, pela compreensão que o empreendedor supõe que possui um direito sobre o corpo e o trabalho de um ou mais indivíduos. O que faz partimos da compreensão sobre escravidão a partir do artigo 149 do código penal brasileiro - Reduzir alguém a condição análoga à de escravo, quer submetendo-o a trabalhos forçados ou a jornada exaustiva, quer sujeitando-o a condições degradantes de trabalho, quer restringindo, por qualquer meio, sua locomoção em razão de dívida contraída com o empregador ou preposto [...].

${ }_{3}^{3}$ Muitos são empreendimentos pertencentes a empresas nacionais e internacionais, que possuem o agronegócio como financiamento paralelo a outros, fomentando a complexa teia de capitais atuantes no Oeste da Bahia e reforçando a necessidade de interpretarmos o território por meio da luta de classes.

Estudos Geográficos, Rio Claro, 17: 176-192, jan./jun. 2019 (ISSN 1678-698X) http://www.periodicos.rc.biblioteca.unesp.br/index.php/estgeo
} 
Pois é nessa circunstância que o capital cria em um só tempo essa diversidade de condições para a sua expansão, com a incorporação de terras, águas e trabalhadores em suas relações comerciais. Onde muitas vezes não ocorre por meio de tramites legais, como a compra de uma propriedade regular, uma licença de uso das águas e uma relação de assalariamento com o trabalhador. O que faz prevalecer à grilagem, o uso irracional da água (seja superficial e/ou subterrânea, para irrigação e/ou energia) e superexploração do trabalho, como o exercício da escravidão etc.

Uma circunstância que acontece em regiões como o Oeste da Bahia, em que apesar da expansão capitalista está em curso, o capitalismo não se realiza plenamente, mesmo presente em uma economia capitalista. Isso, por determinados territórios não estarem organizados totalmente com base nesses valores e o capital necessitar dessas relações enquanto parte dos seus processos de acumulação/expansão (MARTINS, 1981).

\section{UM BREVE DEBATE}

O que os arquivos de jornais, os processos do MPF, as entrevistas, a Comissão Pastoral da Terra - CPT, as reportagens online etc., nos mostrou, foram que a escravidão praticada no Oeste da Bahia não é caracterizada apenas por meras infrações trabalhistas, é um crime contra a dignidade humana, que em muitas das ocasiões em que se flagrou essa prática, se identificou os quatro elementos que a legislação brasileira entende como trabalho escravo hoje, como: trabalho forçado, jornada exaustiva, servidão por dívida e condições degradantes. Tais como são apresentados nos dois relatos abaixo, recortados de processos do Ministério Público Federal - MPF referentes à autuação de produtores pela prática do trabalho escravo em suas fazendas.

"Entre os dias 24/09/2012 e 11/10/2012, Nelson Astor Pooter, proprietário da Fazenda Novos Tempos I, em uma unidade de desígnios com o intermediador de mão-de-obra ("gato") Antônio Pereira da Silva, de maneira livre, consciente e voluntária, reduziram 9 (nove) trabalhadores a condições análogas às de escravos, sujeitando-os a condições degradantes e a restrição de liberdade, em razão de supostas dívidas contraídas com os denunciados (Sistema de barracão), para a realização de serviços vinculados à cata de raízes no interior da Fazenda Novos Tempos I, situada na zona rural do município de São Desidério." (MPF, autos $n^{\circ}$ 1.00.000.001836/2013-07)

"Entre os dias 24/09/2012 e 24/10/2012, Helmult Rieger, proprietário da Fazenda Flor da Esperança, em unidades de desígnios com os gerentes-administradores do referido imóvel rural, Lucindo Lissadalpra e Elenilton Luís Hernann, de maneira livre, consciente e voluntária, reduziram 9 (nove) a condições análogas às de escravo, sujeitando-os a condições degradantes e submetendo-os a jornadas exaustivas para a realização de serviços vinculados à colheita do milho - impossibilitado de ser colhido mecanicamente, em decorrência de um pivô incendiado - no interior da Fazenda Flor da Esperança, situada na zona rural do município de São Desidério BA". (MPF, autos $n^{\circ} 1.00 .000 .001659 / 2013-51$ )

Estudos Geográficos, Rio Claro, 17: 176-192, jan./jun. $2019 \quad$ (ISSN 1678-698X) http://www.periodicos.rc.biblioteca.unesp.br/index.php/estgeo 
Foram situações identificadas em variadas atividades econômicas, organizadas em diferentes extremidades se tratando da modernização econômica e técnica do setor dessas ocupações. Com variações do "moderno ao arcaico", que transitam em setores que "por si só" são degradantes, com particularidades na forma de produzir e nas funções dos trabalhadores. Que possuem ao mesmo tempo e de modo paralelo, padrões de produção rudimentares como as carvoarias e atividades de alta qualificação técnica e de gestão, como as fazendas que cultivam as commodities agrícolas. Em uma dinâmica territorial conjunta, em que a supressão da vegetação intuída de fabricar o carvão, possui uma ligação direta a estruturação da área para a prática agrícola ${ }^{4}$, como explica o relato.

"[...] o carvão ele acompanha o avanço do desmatamento, eles são associados. Onde está acontecendo desmatamento ele está ocorrendo. Agora assim, muitas vezes desmatamentos que são legais, autorizados pelos órgãos competentes, eram utilizados para acobertar carvão irregular. [...] nos gerais geralmente, o fazendeiro, o proprietário de terra, ele sede a área para alguém desmatar, inclusive a pessoa que vai desmatar, parte do pagamento é o próprio material lenhoso que ai ele vai produzir carvão e muitas vezes a produção de carvão não está aliado ao proprietário da terra, em poucos casos nós vamos encontrar essa relação, mas na maioria das vezes ele repassa ao terceiro que vai fazer a exploração florestal. [...] aqui na chapada a intenção do grande produtor é usar a terra e não tem como principal objetivo a produção de carvão. É secundária, só para aquele primeiro momento mesmo [...]". (Suassuna, Luís Eduardo Magalhães, junho de 2014).

A degradação ambiental provocada inicialmente pelo desmatamento acompanha em ritmo acelerado e paralelo a deterioração da espécie humana. É nesse caminho que formas de trabalho degradantes também são construídas, pois a supressão da vegetação segue as rotas do trabalho análogo ao escravo na região, vinculados principalmente a "limpeza" de novas áreas desmatadas para o cultivo das commodities e ao mesmo tempo, o aproveitamento da madeira para a fabricação de carvão vegetal. São rotas do trabalho escravo e/ou degradante, em que proprietários necessitam de mão-de-obra braçal para a retirada de troncos e raízes, não retiradas no ato do desmatamento ou da queimada.

Unanimemente, todas as informações coletadas informaram que a maioria das carvoarias foram extintas na região e assim, praticamente se extinguiu o trabalho escravo nesse setor. Contudo, com essa informação, surgiu a seguinte indagação: Se a produção de carvão vegetal no Oeste da Bahia praticamente se extinguiu e a sua produção caminhava paralela aos novos espaços de plantio da fronteira agrícola, qual o "novo" destino da madeira suprimida atualmente, já que o desmatamento continua a ocorrer de modo acelerado e o trabalho escravo continuou a crescer, mesmo em outras atividades até 2013? Essa é uma incógnita sem resposta até esse momento da pesquisa! A única suspeita identificada é que a madeira "ilegal" está sendo queimada e não mais manufaturada. Contudo, sem qualquer materialidade de prova que comprove tal afirmação. O que possibilita a ideia que a madeira suprimida atualmente possa estar presente em outras rotas e

\footnotetext{
${ }^{4}$ A manufatura de carvão vegetal no Oeste da Bahia era fomentada sumariamente pelos capitais ligados ao setor agropecuário enquanto fomentadores da produção, pela linhagem exercida no tramite da supressão da vegetação enquanto mola precursora da disponibilidade de matéria prima e os capitais industriais fabricantes de ferro gusa na região do Quadrilátero Ferrífero em Minas Gerais, enquanto os principais.

Estudos Geográficos, Rio Claro, 17: 176-192, jan./jun. $2019 \quad$ (ISSN 1678-698X) http://www.periodicos.rc.biblioteca.unesp.br/index.php/estgeo
} 
atividades de uso $^{5}$, principalmente com o avanço desenfreado do desmatamento, que continua a ocorrer.

Outro questionamento equivale às infrações trabalhistas no campo do Oeste da Bahia, registradas pelos auditores fiscais do trabalho do MTE. Visto que dos 812 autos registrados entre 2010 e 2014, mais da metade foram ligadas a infrações presentes no artigo 149 do código penal, equivalentes à remuneração, a períodos de descanso, jornada do trabalho e registro de empregado. Uma inquietude do ponto de vista que, a remuneração não cabível de atender as condições básicas dos trabalhadores, as jornadas exaustivas e o não cumprimento com a legislação trabalhista continuam a acontecer. Agora não mais vinculadas às condições degradantes se tratando dos alojamentos precários, a péssima alimentação, a falta de água e outros aparatos do saneamento básico. Porém, uma melhora ofuscada pelo feitio de alguns avanços, mas, que não conseguiu resolver a essência da exploração ${ }^{6}$.

A Figura 01 representa esse paralelo entre o desmatamento e o trabalho escravo no Oeste da Bahia, reforçando as incógnitas apresentadas. Já que segundo as informações levantadas, desde a segunda metade da década de 2010, quando ocorreu um drástico declínio das carvoarias, houve um aumento expressivo do trabalho escravo (Tabela 01), sobretudo em locais da fronteira agrícola já consolidados do ponto de vista da cadeia produtiva, como as fazendas de grandes grupos empresariais nacionais e multinacionais. Isso como prova que a prática do trabalho escravo pelas grandes empresas é uma das expressões da necessidade de se reconhecer a ampla diversidade de características das relações de trabalho na sociedade capitalista. Nesse caso, com a admissão que essas empresas podem aumentar seus lucros com explorações que não sejam apenas de maneira institucional, formal, contratual e livre.

As contradições do capital em seus processos de reprodução ampliada possuem formas sociais "ilegais" e manifestações formais institucionalizadas, como a escravidão e o "trabalho assalariado livre". Em que as formas coercitivas extremadas da exploração capitalista (MARTINS, 2014) emergem onde o conjunto de processos da reprodução capitalista não encontram obstáculos para tal feito por condições de alguma organização social que possam impedir tais atos, seja estatais e/ou da sociedade civil organizada. Condição que ocorreu na maior parte do intervalo de tempo de abertura da fronteira agrícola no Oeste da Bahia. Pois, só a partir de 1995 o Estado brasileiro iniciou a fiscalização referente ao combate ao trabalho escravo no Brasil (de modo bastante deficiente em relação à demanda existente).

A forma incipiente de fiscalização diante da falta de estrutura dos órgãos competentes frente à alta demanda, licenciou esses grandes empreendedores nacionais e/ou estrangeiros, instaurados sobre os antigos latifúndios

\footnotetext{
${ }^{5}$ A madeira suprimida no Oeste da Bahia não possuía a fabricação de carvão vegetal nesse território, como fim único e exclusivo. Grande parcela era destinada também para a região do "Quadrilátero Ferrífero" em Minas Gerais, destinadas as caldeiras das fábricas de ferro.

${ }^{6}$ É preciso reconhecer os avanços no combate ao trabalho escravo no Brasil como um todo, sobretudo com a criação do Grupo Móvel em 1995 e a ascensão das suas práticas a partir de 2003. Porém, são melhorias que não ataca a essência do trabalho escravo do ponto de vista estrutural (SANTOS, 2011). Como disse Frei Xavier Plassat - Libertar 100 escravos, 1000 escravos ou 40.000, como aconteceu desde 1995, não erradica a escravidão. Ela é um sistema que tem raízes profundas e mecanismos eficazes para garantir sua reprodução: ganância, miséria, impunidade, um ciclo onde cada elemento é produtor e gerador dos demais (INSTITUTO HUMANISTA UNISINOS, 2011).

Estudos Geográficos, Rio Claro, 17: 176-192, jan./jun. 2019 (ISSN 1678-698X) http://www.periodicos.rc.biblioteca.unesp.br/index.php/estgeo
} 


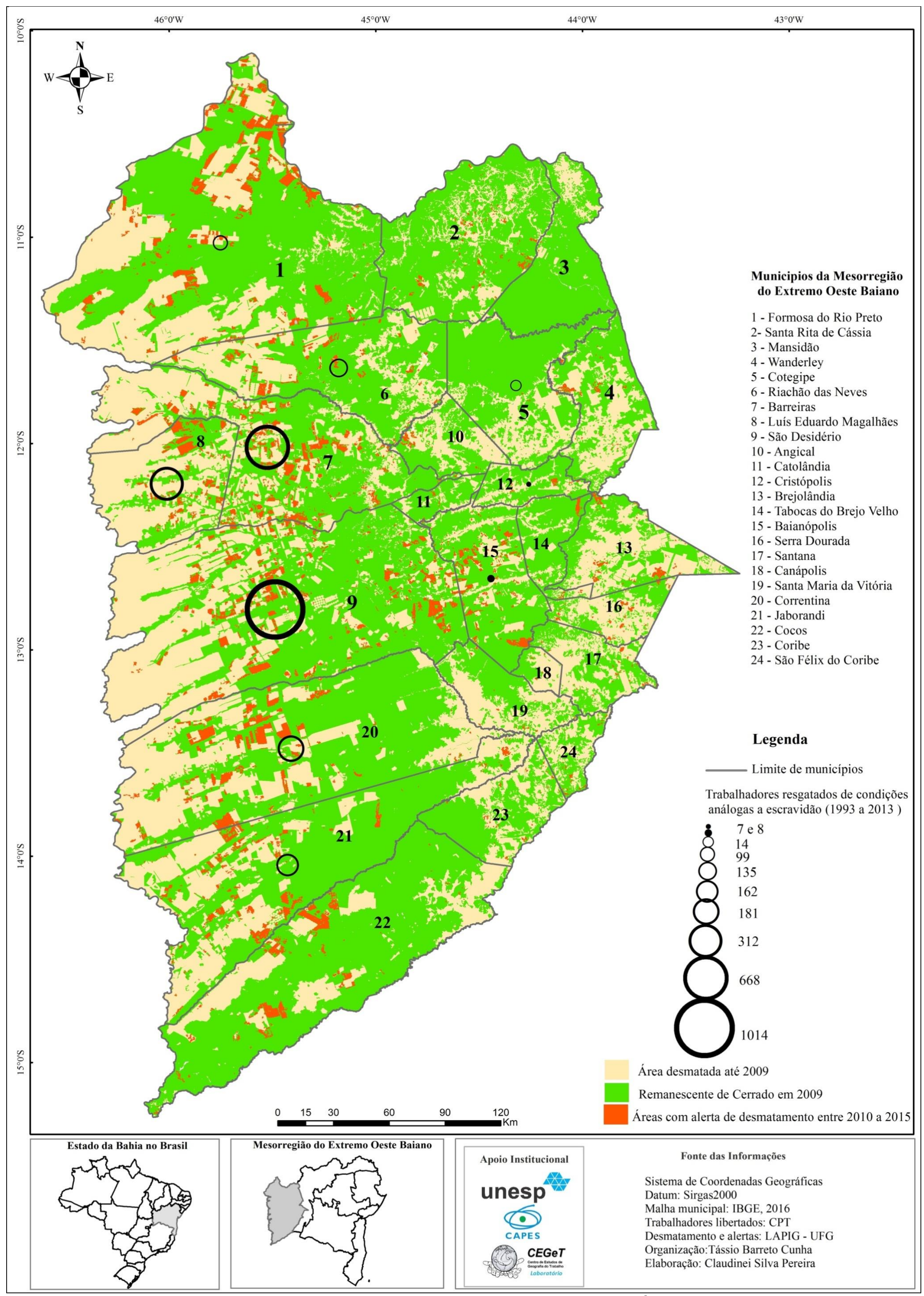

Figura 01 - Avanço do desmatamento e a quantidade de pessoas escravizadas por município no Oeste da Bahia 
Trabalho escravo e a insanidade desumana...

Tabela 01 - Registro de Ocorrências de Trabalho Escravo no Oeste da Bahia

\begin{tabular}{|c|c|c|c|c|c|}
\hline Ano & Município & Nome do Imóvel & Proprietário & № Trabalhadores na Denúncia & № Trabalhadores Libertados \\
\hline 1993 & Barreiras & Fazenda Viqs & Sem Informação & 450 & 450 \\
\hline 2003 & Barreiras & Faz. Cassol / Sto Antônio & João Antônio Franciosi & 46 & 46 \\
\hline 2003 & LEM & Faz. Tabuleiro & André Gomes Ribas & 259 & 259 \\
\hline 2003 & LEM & Faz. Santo Antônio & Sem Informação & 5 & Sem Informação \\
\hline 2003 & São Desidério & Faz. Laranjeiras & Eustáquio da Silveira Vargas & 39 & 39 \\
\hline 2003 & São Desidério & Faz. Roda Velha & Ernesto Dias Filho & 745 & 745 \\
\hline 2005 & Baianópolis & Faz. Errejota/Terra Nova/Galiléia & José Tarciso de Souza & 8 & 8 \\
\hline 2005 & Correntina & Faz. Guará do Meio & João Henrique Meneguel & 68 & 68 \\
\hline 2005 & Cotegipe & Campo Grande do Rio do Largo I & Cofergusa & 3 & 3 \\
\hline 2005 & Cotegipe & Campo Grande do Rio do Largo I & New Fruit Agroind. LTDA. & 11 & 11 \\
\hline 2005 & $\begin{array}{c}\text { Formosa do Rio } \\
\text { Preto }\end{array}$ & Faz. Nossa Senhora Aparecida & Jorge e Fábio Lauck & 39 & 39 \\
\hline 2005 & $\begin{array}{c}\text { São } \\
\text { Desidério/Baianópolis }\end{array}$ & Faz. St" ${ }^{a}$ Clara/Progresso/Esperança & Leliano Sérgio Andrade/Claudete & 21 & 21 \\
\hline 2007 & Barreiras & Fazenda Campo Aberto & Ricardo Ferrigno Teixeira e outros & 82 & 82 \\
\hline 2007 & Riachão das Neves & Fazenda Olinda & Sem Informação & 15 & 15 \\
\hline 2007 & São Desidério & Fazenda Bananal & José Alípio Fernandes da Silveira & 5 & 5 \\
\hline 2007 & São Desidério & Condomínio Agropecuário Ceolin & Regis Francisco Ceolin & 65 & 65 \\
\hline 2007 & São Desidério & Fazenda Holnik/Holink & Adevir Holink & 8 & 8 \\
\hline 2008 & $\begin{array}{c}\text { Formosa do Rio } \\
\text { Preto }\end{array}$ & Fazenda Ramalho II & Ademar Pinto da Costa & 10 & 10 \\
\hline 2008 & Riachão das Neves & Carvoaria/Faz. Sertânia & $\begin{array}{c}\text { Euvaldo de Souza Pereira e Paulo José } \\
\text { Theófilo }\end{array}$ & 38 & 38 \\
\hline 2008 & São Desidério & Faz. da Agrícola Xingu LTDA & Agrícola Xingu Ltda & 12 & 12 \\
\hline 2008 & São Desidério & Fazenda Guarani & Jair Donadel & 27 & 27 \\
\hline 2008 & São Desidério & Fazenda São Francisco & Lauro Trombini & 7 & 7 \\
\hline 2009 & Correntina & Fazenda Santa Angélica & Marilane Moresco Denardim & 14 & 14 \\
\hline 2009 & $\begin{array}{c}\text { Formosa do Rio } \\
\text { Preto }\end{array}$ & Fazenda Vitória & Terezinha Lazarim & 5 & 5 \\
\hline
\end{tabular}


Trabalho escravo e a insanidade desumana...

\begin{tabular}{|c|c|c|c|c|c|}
\hline 2009 & Jaborandi & Carvoaria da Rotavi & Rotavi Industrial Ltda & 154 & 154 \\
\hline 2009 & Jaborandi & Fazenda Santa Vitória & Nestor Hermes & 8 & 8 \\
\hline 2009 & São Desidério & Fazenda São Carlos VI & Paulo Edgar Closs & 14 & 14 \\
\hline 2010 & Barreiras & Fazenda MF2 & Marcondes Antônio Tavares de Farias & 40 & 40 \\
\hline 2010 & $\begin{array}{c}\text { Luiz Eduardo } \\
\text { Magalhães }\end{array}$ & Fazenda Guarani & Belmiro Catelan/Jair Donadel & 44 & 44 \\
\hline 2010 & São Desidério & Carvoaria na Fazenda Beija Flor & Alexandre/ Carvobrás Agrícola Ltda & 12 & Sem Informação \\
\hline 2011 & Barreiras & Fazenda Santa Rita 2 & Alcindo José Dalcin & 21 & 21 \\
\hline 2011 & Correntina & $\begin{array}{l}\text { Brasilago/Companhia Brasileira de } \\
\text { Propriedades Agrícolas }\end{array}$ & José Carlos Arrighi & 23 & 23 \\
\hline 2011 & Correntina & Alfio Gabriel Thomaselli Filho & José Carlos Arrighi & 30 & 30 \\
\hline 2011 & Cristópolis & Fazenda Barcelona & José Carlos Arrighi & 7 & 7 \\
\hline 2011 & $\begin{array}{c}\text { Formosa do Rio } \\
\text { Preto }\end{array}$ & Fazenda Terra Nova & Marcão & 12 & Sem Informação \\
\hline 2011 & LEM & Rocha e Silva Madeireira e Construção Ltda & Rocha e Silva Madeireira e Construção Ltda & 4 & 4 \\
\hline 2011 & Riachão das Neves & Fazenda Garcia & Elton Nunes Garcia & 2 & 2 \\
\hline 2011 & São Desidério & Fazenda Kobra & Sem Informação & 40 & 0 \\
\hline 2012 & $\begin{array}{l}\text { Formosa do Rio } \\
\text { Preto }\end{array}$ & Fazenda Itambi II e III & Roberto Kumasaka & 4 & 4 \\
\hline 2012 & $\begin{array}{l}\text { Formosa do Rio } \\
\text { Preto }\end{array}$ & Fazenda Recreio & Laércio Tagliari Bortolin & 8 & 8 \\
\hline 2012 & $\begin{array}{c}\text { Formosa do Rio } \\
\text { Preto }\end{array}$ & Fazenda Olho Mágico I & João Carlos Burin & 21 & 21 \\
\hline 2012 & Riachão das Neves & Fazenda São Francisco & Ademar Antônio Marçal & 80 & Sem Informação \\
\hline 2012 & São Desidério & Fazenda Flor da Esperança & Helmuth Rieger & 9 & 9 \\
\hline 2012 & São Desidério & Fazenda Novos Tempos I & Nelson Astor Pooter & 10 & 10 \\
\hline 2013 & Barreiras & Fazenda MS1/Mauricéa Alimentos & Sem Informação & 29 & 33 \\
\hline 2013 & Correntina & Fazenda Itaiquara & Sem Informação & 46 & Sem Informação \\
\hline Total & - & 50 registros & - & 2600 & 2409 \\
\hline
\end{tabular}


improdutivos, a praticarem de modo demasiado o uso de mão-de-obra escrava. Circunstancia que se intensificou no intervalo de tempo analisado, com a variação de crescimento ligada diretamente a intensidade de fomento financeiro do Estado. Em que, a maior injeção de capital no setor agropecuário, se deu de modo paralelo a um maior aliciamento de trabalhadores. Fato ligado a um hall de questões políticas, econômicas e sociais apresentadas aqui, que deslumbraram na exacerbação dessa degradante e insana condição de trabalho.

A Figura 01 e a Tabela 01 deixam expressas essas ideias, quando apresentam a distribuição dos registros do trabalho escravo por município, a temporalidade e os responsáveis. Em um cenário que demonstra o trabalho escravo ligado ao avanço da fronteira agrícola, movida pelo aumento da injeção de capitais no campo, com uma aliança interligada entre as carvoarias e o agronegócio. Concepção expressada pelos tipos de empreendimentos que ocorreram os registros, seus respectivos locais e os anos. Ou seja, são em fazendas do agronegócio e carvoarias ${ }^{7}$, localizadas em municípios produtores de commodities agrícolas e a partir da década de 2000, que a prática do trabalho escravo no Oeste da Bahia vai ser identificada com maior pujança, com 2409 trabalhadores libertados pelas operações do Grupo Especial de Fiscalização Móvel - GEFM. Número correspondente a 90,9\% do trabalho escravo catalogado na Bahia $^{8}$ entre 2003 e $2013^{9}$ (CPT - JORNAL CORREIO, 2014).

Essa situação reforça o argumento que a escravidão atual no Oeste da Bahia é um componente do próprio capital e que essa opção é condicionada sumariamente pela luta de classes no âmbito da tríade Estado-CapitalTrabalho, conectada diretamente nas circunstâncias de desenvolvimento do capital e sua reprodução ampliada. Em que as posições históricas - políticas, econômicas e sociais do Estado brasileiro e baiano, alheias a esse processo acumulativo financeiro vigente, são centrais na estruturação dessas ocasiões. Visto que a manutenção de uma estrutura fundiária extremamente concentrada, a flexibilização trabalhista, a submissão econômica global, a omissão frente à degradação do trabalho e da natureza, a tentativa de "gerir a barbárie social" (MENEGAT, 2006), a opção pela primarização da economia como protagonista na balança comercial etc., são questões chaves para embasarmos a ideia que essas relações de trabalho não capitalistas, não destituídas pelo modo de produção vigente, é essencialmente produto do próprio capital. Pois, como disse Martins (2011), "o capital é capitalista, mas o modo de obtê-lo pelo trabalho escravo não é".

Essa condição é possível porque o salário "acertado" entre patrão e o trabalhador escravizado, não dar a possibilidade para que os meios de vida necessários à produção da força de trabalho sejam adquiridos e regulados pela mediação do mercado, enquanto uma condição que determinaria as relações capitalistas de produção. Pois, o salário que entra na contabilidade do

\footnotetext{
${ }^{7}$ No período entre 2003 e 2013 as atividades realizadas em carvoarias (18\%); no cultivo do algodão herbáceo (17\%); no preparo do terreno (catadores de raízes) (13\%); cultivo do milho milho (13\%); cultivo da soja (9\%); o desmatamento $(5 \%)$ e no cultivo do café (5\%), foram as que mais apresentaram registros de trabalhadores escravizados (COUTINHO; GERMANI \& OLIVEIRA, 2013).

${ }^{8}$ Segundo os órgãos atuantes no combate ao trabalho escravo no Oeste da Bahia, esse número pode ser 4 a 5 vezes maior, por serem diversos os trabalhadores fugitivos, descartados e até mortos durante o período de coação.

${ }^{9}$ Esse período é contabilizado porque é a partir de 2003 que o GEFM começa a atuar no Oeste da Bahia, com registros de trabalho escravo até 2013.

Estudos Geográficos, Rio Claro, 17: 176-192, jan./jun. 2019 (ISSN 1678-698X) http://www.periodicos.rc.biblioteca.unesp.br/index.php/estgeo
} 
capitalista nessa temporalidade de escravidão temporária ${ }^{10}$, não é transferido para o trabalhador por conta das formas coercitivas extremadas, pensadas para escravizar o trabalhador atualmente. Logo, essa não transferência impossibilita a produção de uma relação capitalista que gere a mais-valia por meio do assalariamento. Em uma condição de inclusão voltada para o trabalho degradante e não para o consumo (MARTINS, 2012; MARTINS, 2014 \& MARTINS, 2015).

O trabalho escravo no Oeste da Bahia foi tão usual no período analisado, que floresceu em variados setores no campo e na cidade ${ }^{11}$, que segundo as informações coletadas (processos do MPT, dados MTE referente à origem $^{12}$ dos trabalhadores escravizados, arquivos de jornais, reportagens online, entrevistas, cadernos da CPT etc.) a maioria dos grupos libertados são de trabalhadores da própria região e migrantes, com predomínio desses transumantes da própria Bahia. Um cenário de "mão-de-obra farta" diante do consentimento e omissão estatal e das condições de marginalidade social existente no Oeste da Bahia, nas fronteiras estaduais que limitam institucionalmente esse território (Nordeste do Goiás, Sudeste do Tocantins e Sul do Piauí e Maranhão) e no Estado baiano como um todo.

A Figura 02 e 03 expõe essa dinâmica do fluxo de trabalhadores escravizados dos seus lugares de origem para o Oeste da Bahia. O que mostra movimentos internos da própria Bahia, na região Oeste e entre os estados fronteiriços. Um movimento paralelo que trabalhadores recrutados em locais isolados se juntam com trabalhadores da própria região e em alguns casos, com outros do mesmo município, em áreas da fronteira já consolidadas, próximas até mesmo das sedes municipais, dado que $80,16 \%$ dos trabalhadores escravizados foram resgatados nos municípios de São Desidério $(39,52 \%)$, Barreiras $(27,89 \%)$ e LEM $(12,73 \%)$. Números que reforçam o argumento que enquanto mais a fronteira agrícola se consolidar, maior será os agraves frente ao trabalhador. Pois, a precarização das relações, a degradação do trabalho e a escravização são frutos do mesmo processo, que impulsiona a lógica acumulativa vigente. Claramente comprovado no Oeste da Bahia, quando cruzamos as informações dessas variáveis entre os municípios da região.

Uma emergência de trabalhadores escravizados que "aflorou como maxixe em época de inverno bom", estruturada pela abundância de mão-deobra em territórios que a extrema pobreza reinava no início da década passada e pela própria condição subalterna de muitos trabalhadores, que em alguns

\footnotetext{
${ }^{10}$ É uma das formas mais dramáticas de migração, que está interligada diretamente no processo de degradação dos homens e mulheres vinculados diretamente na reprodução ampliada do capital, que inclui para trabalhar, degradar, precarizar e até morrer, e exclui para um "melhor viver". Em uma dinâmica desterritorializante, que além de desvincular o trabalhador dos seus laços socioculturais, relações afetivas, profissão etc., o descarta como "poeira ao vento", "sem lenço e sem documento", após o termino dos serviços e/ou das fugas.

${ }^{11}$ Não foi exposto na Tabela 01 a prática do trabalho escravo por setor econômico no Oeste da Bahia, porque as fontes consultadas (CPT, MTE e ONG Repórter Brasil) não disponibilizaram os dados na íntegra. A CPT não expõe essa informação em sua catalogação e as outras duas fontes retiram esse dado após o nome do acusado ser desligado da "lista suja do trabalho escravo" do MTE. Contudo, pelos nomes dos empreendimentos apresentados na Tabela 01, é possível perceber que os registros do trabalho escravo nessa região predominaram no campo no período exposto, principalmente nas fazendas do agronegócio e nas carvoarias. Contudo, houve um registro no urbano, com a escravização de 4 trabalhadores pela Rocha e Silva Madeireira e Construção Ltda., em 2011 na cidade de LEM.

${ }^{12}$ Os trabalhadores identificados como escravos no Brasil, atualmente recebem 3 meses de seguro desemprego e é cadastrado no programa Bolsa Família. Esses, enquanto os primeiros passos para incentivar a ressocialização do indivíduo e mitigar a possibilidade de ser escravizado novamente, pois possuirá renda mínima e ideia de como funciona o trama da escravidão moderna, do aliciamento a prisão.

Estudos Geográficos, Rio Claro, 17: 176-192, jan./jun. 2019 (ISSN 1678-698X) http://www.periodicos.rc.biblioteca.unesp.br/index.php/estgeo
} 
casos contribuíram para a não rebeldia desses indivíduos, até mesmo pela inconsciência que estavam sendo escravizados.

Uma dinâmica potencializada pela pobreza em seus locais de origem (emergentes principalmente do campo e de pequenas cidades), em condições muitas vezes extremas, com casos que as condições de trabalho chegam a serem similares às vivenciadas quando escravizados. Sendo a parti dessa situação que em alguns casos identificados, trabalhadores resgatados não conseguiram entender esse regime de trabalho enquanto servil, sobretudo aqueles que foram condicionados a jornadas exaustivas e a servidão por dívida. Visto que as altas cargas de trabalho e o princípio da "honra da palavra" eram inerentes ao cotidiano de vida de muitas dessas pessoas, "inconscientes coniventes com a escravidão". Como disse Martins (2011): "a perversidade está em fazer da vítima cumplice da perversão".

As características socioeconômicas dos trabalhadores escravizados segue o perfil dos indivíduos vitimados diretamente na degradação do trabalho no campo do Oeste da Bahia. Em um receptáculo que predomina o sexo masculino adulto ${ }^{13}$, "ora camponês, ora operário", com perfil familiar patriarcal, descendentes de estados fronteiriços e principalmente da própria Bahia, como apresentam as Figura 02 e 03.

Contudo, ao mesmo tempo em que o trabalhador escravizado possa imaginar que a sua migração temporária em algum momento lhe proporciona um ganho de renda inexistente em seu lugar de origem, não reconhecendo o estado servil que tenha vivenciado, a sua consciência em algum momento pode se atinar a realidade e tornar uma possível intervenção para muda-la, já que a consciência possui um real poder no plano do ser (LUCÁKS, 1968). É nesse sentido que o reconhecimento da servidão pelos trabalhadores pode partir do momento que o trabalhador se dar conta da falta de liberdade pelas dívidas, as ameaças, as torturas e mortes como o relato abaixo descreve. Em um devir que a consciência da escravidão pode ser interpretada a partir de uma grande variedade de circunstâncias, tanto da forma que o trabalhador for alvejado, quanto da sua performance em agir.

Nesse cenário de barbárie e descarte de humanos que a escravidão atual se mostra em muitos sentidos, pior que a escravidão adotada até o século XIX. Sobretudo porque o entendimento do trabalhador reificado e escravizado, licencia o seu trato como um mero objeto descartável, que irá servir para aquele que the escravizar, apenas durante um curto período. Ou seja, um objeto irrelevante e passageiro do ponto de vista do capital, já que não é visto enquanto capital fixo como na era da escravidão institucionalizada. Situação que de certo modo obrigava o proprietário do escravo ter certos cuidados do ponto de vista material, já que possuía valor. Lógico que não estamos negando a matança, os espancamentos, as prisões, as rebeldias, porque estaríamos se opondo a própria chave do entendimento - a história. Porém, no quesito do cuidado do corpo, visto como matéria e mercadoria, esse é o nosso ponto de vista.

As Figuras 02 e 03 que sobrepostas mostram os fluxos dos trabalhadores escravos para o Oeste da Bahia a partir dos seus lugares de origem na Bahia e nos Estados fronteiriços, corroboram com esse argumento a partir do momento que se conhece a realidade de parte considerável dos locais

\footnotetext{
${ }^{13}$ Segundo Coutinho; Germani \& Oliveira (2013), os homens correspondem a 96\% dos trabalhadores resgatados. Estudos Geográficos, Rio Claro, 17: 176-192, jan./jun. 2019 (ISSN 1678-698X) http://www.periodicos.rc.biblioteca.unesp.br/index.php/estgeo
} 
da origem dos trabalhadores e os territórios nos quais foram escravizados. Em uma trama que "se correr o bicho pega e se ficar o bicho come", visto que os estados limítrofes com o Oeste da Bahia e os Territórios de Identidade da Bahia que enviam trabalhadores são espaços que vivenciam condições sociais do ponto de vista trabalhista, de modo bastante similar, da penúria a degradação do trabalho. O que é ratificado pelo relato de um empresário sulista ainda na década de 1990 na cidade de Barreiras, quando fala da migração de pessoas da região de Irecê para o Oeste da Bahia. 
Trabalho escravo e a insanidade desumana...

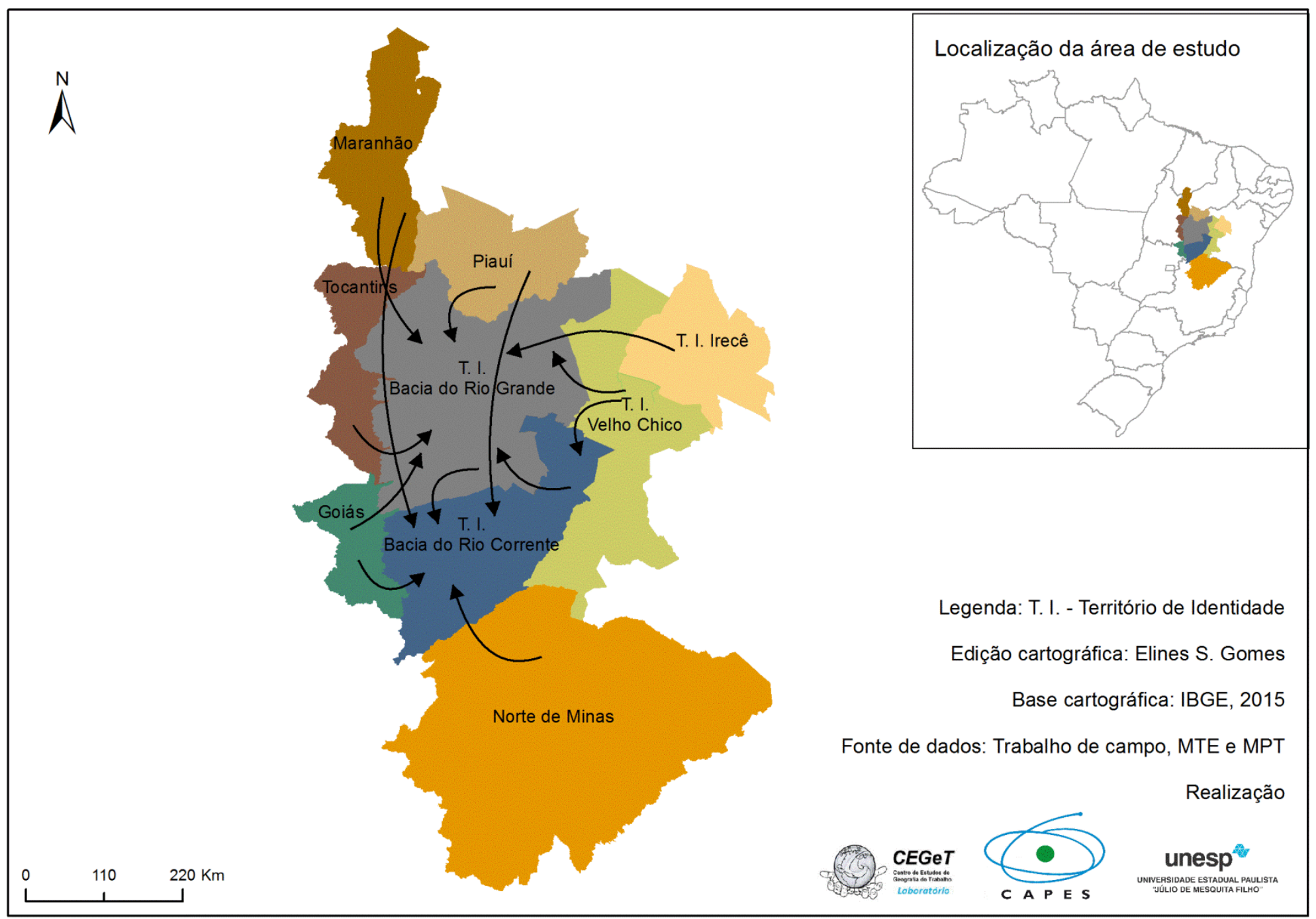

Figura 02 - Fluxo do trabalho escravo no Oeste da Bahia

Fonte: Trabalho de Campo, MPT, MTE e CPT. 


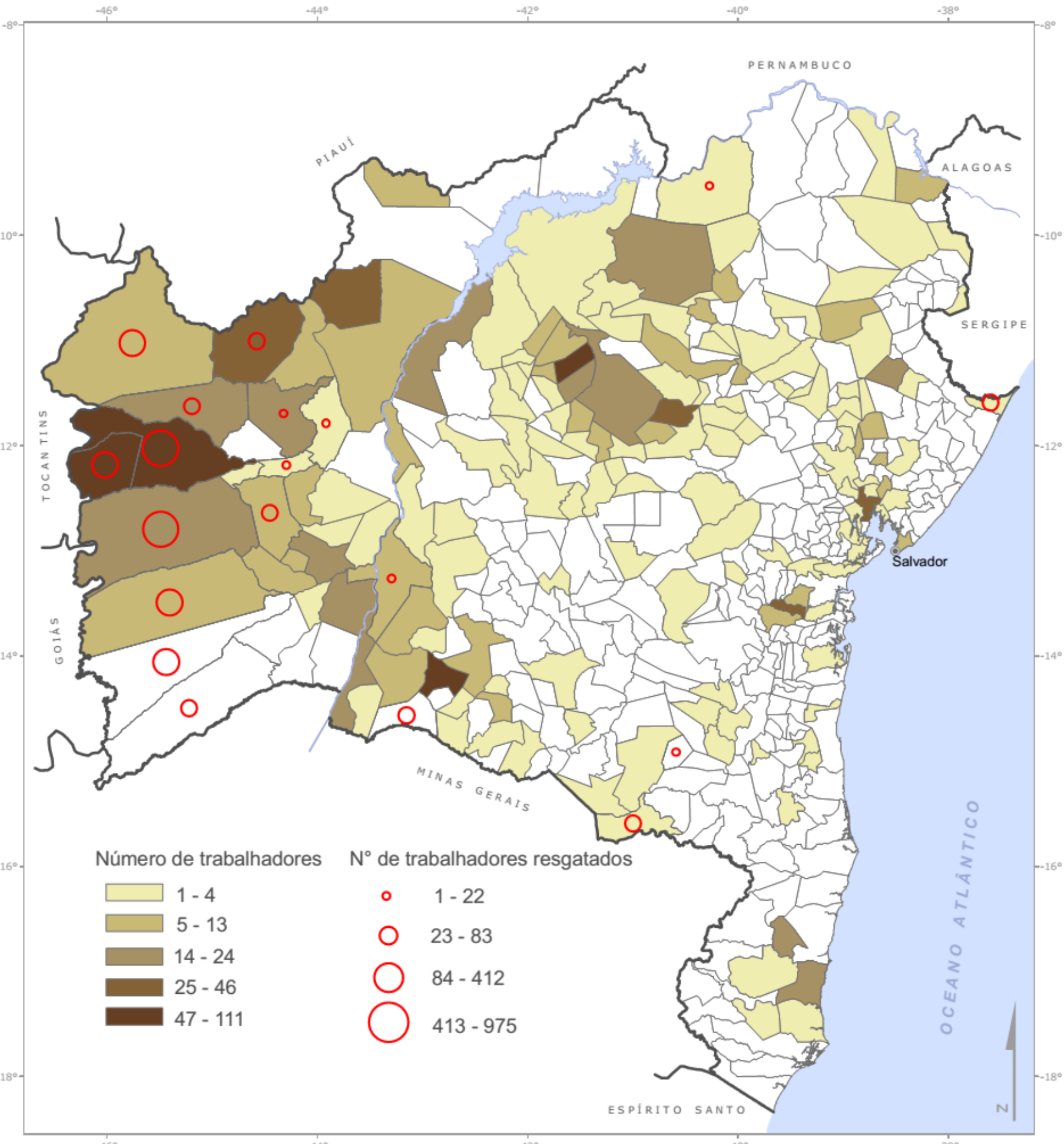

Figura 03 - Origem de Trabalhadores Escravizados e o município de resgate entre 2003 e 2011 na Bahia, segundo o MTE

Fonte: Geografar - UFBA.

Estudos Geográficos, Rio Claro, 17: 176-192, jan./jun. 2019 (ISSN 1678-698X) http://www.periodicos.rc.biblioteca.unesp.br/index.php/estgeo 
lembro agora o $\mathrm{n}^{\circ}$ de trabalhadores... e esses dois rapazes ficaram no mercado central de Baianópolis, não quiseram ficar na fazenda temendo a própria vida." (Risalva, Barreiras, junho de 2014).

"Muito caminhão pra cá vem de Irecê, aquela região do feijão. Existe aquela famosa malandragem, aquela piada que muitos contam, mas poucos a levam a sério: qual é a melhor forma de você tirar um, carregar um favelado da porta da sua casa? É você prometer uma coisa boa pra ele, botar dentro de um ônibus com passagem só de ida. Ele não volta mais porque não tem dinheiro. É a melhor forma de você tirá-lo da porta da sua casa. Botam caminhões com 50, 60 pessoas em cima e largam aqui e vão embora." (Relato extraído de Haesbaert, 1995).

A sobreposição das figuras, tabelas e o restante das informações apresentadas nesse capítulo, mostram a dinâmica do aumento da informalidade do trabalho, da degradação dos processos, da precarização das relações, da escravização etc., que se encontram no bojo de um todo impulsionado pela não responsabilidade social e moral dos representantes do capital frente ao trabalhador, com a culpabilidade dirigida para o indivíduo em si. Em uma constância de consequências patológicas, de marginalidade social e de uma miséria moral sem limites por parte do capital, onde a espécie humana é posta na base da hierarquia de importâncias, sobreposta por qualquer variável econômica que possa contribuir com a ascensão da taxa de lucro. Com uma forma de tratamento da maneira "mais tacanha que se possa existir". "Não é atoa" que a escravização de 35,8 milhões de pessoas no mundo em 2014 é considerada uma epidemia mundial, visto que 155 mil são brasileiros, em maioria baianos, e que no território da Bahia a "boca do caldeirão" se encontra na sua porção Oeste (ONG Walk Free - BBC, 2014). Isso somado ao absurdo que milhares dessas pessoas escravizadas são crianças e estão vinculadas a serviços de grandes multinacionais com quase total anomia.

\section{PASSOS (IN) CONCLUSOS}

É nesse contexto territorial da degradação do trabalho no Oeste da Bahia, pensado a partir do conjunto social de referência dos trabalhadores, que se observa toda essa temeridade com a espécie humana, seja nas "entocas" das fazendas isoladas ou nas periferias dos polos de atração. Com uma imposição de valores cultivados pela ânsia burguesa, em um sentido de "faça o que eu digo, mas não faça o que eu faço". Ou seja, uma lógica de impossível inclusão das massas, com o descarte da maioria, que pela falta de políticas públicas não alcançam a necessária ascensão social. Junto a uma "pobreza que se mescla no lixo dos ricos", em que os pobres se movem entre os resíduos e rejeitos da abundância, "dos que tudo tem e dos que tudo podem". Com a inversão de valores de que - "antes trabalhava-se para subir na vida e agora trabalha-se para atenuar o tempo de queda, em que muitas vezes o próprio trabalho já faz parte do processo de queda" (MARTINS, 2012).

Estudos Geográficos, Rio Claro, 17: 176-192, jan./jun. 2019 (ISSN 1678-698X) http://www.periodicos.rc.biblioteca.unesp.br/index.php/estgeo 
"Nós somos partidários da república democrática como sendo a melhor forma de governo para o proletariado sob o regime capitalista, mas andaríamos mal se esquecêssemos que a escravidão é o quinhão do povo, mesmo na república burguesa mais democrática."

(Vladimir llyitch Ulianov - Lênin)

\section{REFERÊNCIAS}

BBC BRASIL. Brasil tem 155 mil pessoas em situação de escravidão, diz ONG. 17 de novembro de 2014.

COUTINHO, Elen da Silva; GERMANI, Guiomar Inez \& OLIVEIRA, Gilca Garcia. Expansão da Fronteira Agrícola e suas relações com o Trabalho Análogo a de Escravo no Oeste da Bahia. Brasiliana - Journal for Brazilian Studies. Vol. 2, $n^{\circ} 2$, 2013.

HASBAERT, Rogério Costa. “Gaúchos” no Nordeste: Modernidade, DesTerritorialização e Identidade. Tese de doutorado em geografia, Universidade de São Paulo - USP, Departamento de Geografia. 1995.

INSTITUTO HUMANISTA UNISINOS. Trabalho escravo no Brasil: uma herança maldita do capitalismo. Entrevista especial com Frei Xavier Plassat. 17 de Março de 2017.

LÊNIN, Vladimir Ilyich Ulyanov. As classes sociais e o Estado. In. O Estado e a revolução. São Paulo - SP. Hucitec. 1983.

LUKÁCS, György. As bases ontológicas do pensamento e da atividade do homem. Tradução de Carlos Nelson Coutinho, 1968.

JORNAL CORREIO 24 HORAS. Escravidão: Extremo-Oeste registrou 90,9\% dos casos na Bahia em 10 anos. Salvador - BA, 21 de abril de 2014.

MARTINS, José de Souza. A sujeição da renda da terra ao capital e o novo sentido da luta pela reforma agrária. In. Os camponeses e a política no Brasil: As lutas sociais no campo e o seu lugar no processo político. Ed. Vozes, 5a edição. Petrópolis - RJ. 1981.

Paulo - SP. Ed. Contexto. 2015.

O cativeiro da terra. $9^{a}$ edição, $2^{a}$ reimpressão. São

FRONTEIRA: a degradação do outro nos confins do

humano. $2^{\underline{a}}$ edição, $2^{\mathfrak{a}}$ reimpressão. São Paulo - SP. Ed. Contexto. 2014.

A sociedade vista do abismo: novos estudos sobre exclusão, pobreza e classes sociais. 4ª edição. Petrópolis - RJ. Vozes. 2012.

Estudos Geográficos, Rio Claro, 17: 176-192, jan./jun. 2019 (ISSN 1678-698X) http://www.periodicos.rc.biblioteca.unesp.br/index.php/estgeo 
MENEGAT, Marildo. O olho da barbárie. São Paulo - SP. Expressão Popular. 2006.

MÉSZÁROS, István. O Desafio e o Fardo do Tempo Histórico. São Paulo - SP. Boitempo, 2007.

MINISTÉRIO PÚBLICO FEDERAL - MPF: autos $n^{\circ}$ 1.00.000.001836/2013-07. Procuradoria da República em Barreiras - BA. 2013.

Procuradoria da República em Barreiras - BA. 2013.

SANTOS, Ludiara Fernanda Borba dos. O papel do Estado no combate ao trabalho análogo ao de escravo na Bahia. Dissertação de Mestrado Universidade Federal da Bahia - UFBA, Faculdade de Ciências Econômicas. Salvador - BA. 2011. 